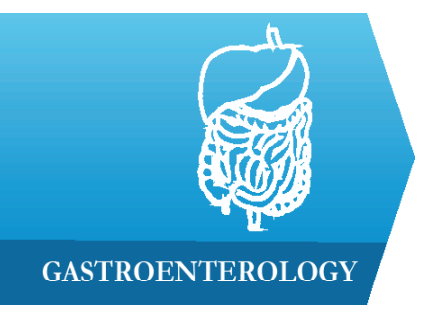

$2^{\text {nd }}$ Medical Department, Iuliu Hatieganu University of Medicine and Pharmacy, Cluj-Napoca, Romania
DOI: $10.15386 / \mathrm{mpr}-1370$

Manuscript received: 22.05 .2019

Received in revised form: 20.11.2019

Accepted: 10.12.2019

Address for correspondence:

ddumitrascu@umfcluj.ro

This work is licensed under a Creative Commons Attribution-NonCommercialNoDerivatives 4.0 International License

\section{High prevalence of gastroesophageal reflux in vocal opera students. A case-control type study}

\author{
Alexandra Corojan Loor, Sebastian Nedelcuț, Dan Lucian Dumitraşcu
}

\begin{abstract}
Background. Opera singers are at risk to develop gastroesophageal reflux, because of the vocational challenges during singing. The singers are reluctant to be submitted to $\mathrm{pH}$-metry fearing throat injuries. We evaluated the gastroesophageal reflux in vocal opera students using a non-invasive salivary test.

Design and setting. A prospective, case-control study was carried out in 30 vocal opera students from the Music Academy of the city Cluj-Napoca, Romania, enrolled in the "canto" section.

Methods. For control, 20 medical students and residents were enrolled. Each subject filled in a questionnaire and gave saliva samples for the salivary test Peptest $^{\mathrm{TM}}$ (RD Biomed). The statistical analysis was made using program $\mathrm{R}$ version 3.2.1 (2015-06-18).
\end{abstract}

Results. According to salivary Peptest, vocal opera students had a higher prevalence of gastro-esophageal reflux than the control group $(96.67 \%$ versus $30 \%$; 29 from 30 vs 14 from 20 ), $\mathrm{P}<0.001$. Only $50 \%$ ( 15 of 30 ) of the vocal opera students reported reflux symptoms.

Conclusions. Salivary Peptest confirmed a higher prevalence of gastroesophageal reflux in vocal opera students, although not all of them reported reflux symptoms.

Keywords: gastroesophageal reflux, saliva, diagnostic test

\section{Introduction}

The Montreal consensus conference defined gastroesophageal reflux disease (GERD), as "a condition which develops when the reflux of gastric contents causes troublesome symptoms and/or complications" [1].

Typical symptoms of GERD are heartburn and acid regurgitation but, in many patients, other digestive symptoms are found, like belching, sialorrhea or sore throat. Other important reflux symptoms include extraesophageal manifestations: pulmonary complications: asthma, chronic cough, ENT manifestations: dysphonia, laryngitis, ulcer and laryngeal polyps, sinusitis, otitis, or non-cardiac chest pain. Still, the most seen GERD complications remain reflux esophagitis and Barrett's esophagus [2].

The pathogenesis of GERD is multifactorial. The most important factors include transient lower esophageal sphincter relaxation, high intraabdominal pressure, reduced esophageal capacitance, low gastric compliance, delayed gastric emptying and impaired esophageal clearance. Gastric juice includes ingested food and drink, acid and digestive enzyme of which the most important is pepsin. All these components can be refluxed from the stomach into the esophagus, larynx and respiratory system. Pepsin, the enzyme responsible for the crude digestion of protein is the main aggressive agent responsible for damaging esophageal and laryngeal tissue during reflux [3-6].

Thus the detection of pepsin in the refluxate is an appropriate objective clinical measurement tool, because it specifically detects the damaging component of gastric refluxate.

Peptest $^{\text {TM }}$ is the world's first noninvasive diagnostic test for reflux disease. 
The Peptest kit is an immunological in-vitro diagnostic medical device that contains two pepsin monoclonal antibodies; it allows you to identify pepsin in a clinical sample of saliva/sputum quickly and easily. This test permits $\mathrm{pH}$ independent identification of patients suffering from gastric reflux. It detects pepsin, with a detection limit of $16 \mathrm{ng} / \mathrm{ml}$ in clinical samples obtained from the upper digestive tract and the respiratory system. The presence of pepsin in these samples is a reliable marker for the reflux of gastric juice. An important aspect is that PPI medication does not influence the test result [7].

The studies conducted on salivary Peptest regarding it's efficacy in diagnosing GERD and extraesophageal manifestation revealed encouraging results [8-13]. Peptest also yielded good results as it respects the diagnosis of extraesophageal reflux in children with chronic otitis media with effusions, a category of patients in whom invasive investigations are much more difficult to perform $[14,15]$.

A study performed in 2019 on more than one thousand patients revealed that the sensitivity of Peptest was high, but the specificity moderate in GERD diagnosis [16]. Others works showed that patients with extraesophageal manifestations of GERD like asthma had higher values of salivary pepsin than controls [17].

Other two studies revealed that salivary Peptest could be a good tool for laryngopharyngeal reflux diagnosis in symptomatic and asymptomatic patients [18,19]. In 2019 Klimara et al. demonstrated that there was a correlation between high salivary pepsin values, and patients with multichannel intraluminal impedance-pH (MII-pH) demonstrated laringopharyngeal reflux [20]. It seems that patients with obstructive sleep apnea present positive tests for salivary pepsin [21].

A special class of patients affected by gastric reflux are opera singers. They perform singing tasks that require rapid changes of subglottal pressure with consistent use of the diaphragm, which causes an abrupt and prolonged increase in intra-abdominal pressure, deep inspiration, and straining. Because the diaphragmatic sphincter is disabled by these mechanisms, repeated over many years of professional activity, the occurrence of reflux symptoms is increased. Opera singers may be at risk to develop GERD because of their effort to sing.

There are several studies regarding this topic who showed that professional opera singers have a statistically significantly higher prevalence of GERD symptoms than control [22-25]. All these studies were performed using scores from different questionnaires related to symptomatology, but no biological test was performed.

\section{Objective}

The purpose of our study was to evaluate GERD in vocal opera students and to compare this aspect with the prevalence of gastresophageal reflux in medical students and residents.
We used a totally noninvasive test, the salivary Peptest, in order to avoid any annoying esophageal catheterization during $\mathrm{pH}$-monitoring.

\section{Methods \\ Subjects}

The study included 30 of 35 vocal opera students from the Music Academy of the city of Cluj-Napoca, Romania, enrolled in the "canto" section. The inclusion criteria were: students from "canto" section, who signed the informed consent, with the age between 19-60 years. The exclusion criteria were: other associated diseases which could produce a gastroesophageal reflux (current gastritis or gastric ulcer, history of gastric or biliary surgery, liver and renal pathology, allergies, respiratory or ENT diseases), 48 hours prior administration of antacids (like Gaviscon for example) and subjects who did not want to take part in the study.

As controls, 20 medical students and residents with a similar distribution of age and sex were recruited.

A symptom evaluation was made, using questionnaires regarding heartburn, cough, epigastric pain, hoarseness and nausea.

\section{Protocol}

This is a prospective, case-control study, undertaken in a single center. All participants filled a demographic questionnaire which was self-completed including sociodemographic data, medical history, lifestyle and symptoms.

Our study was approved by the the Ethics Committee of the Iuliu Haţieganu University of Medicine and Pharmacy Cluj-Napoca Romania. The number of the approval is 526 from 09.02.2016.

After obtaining informed consent, a saliva sample was taken, a minimum of $1 \mathrm{ml}$ into a $30 \mathrm{ml}$ universal sample collection tube containing citric acid to preserve the action of any pepsin present. Each participant took one sample of saliva at least one hour after the meal. All the samples were stored in a refrigeratos according to manufacturer's recommendations and were processed within less than seven days after saliva collection.

The collection tube were centrifuged at $4000 \mathrm{rpm}$ for 5 minutes. From the clear supernatant layer a $80 \mu \mathrm{l}$ was taken and transferred into a microtube containing $240 \mu$ of migration buffer solution. Those samples were mixed with a vortex mixer for 10 seconds. After that, from the last samples using a pipette was applied the same volume on the circular well of the Peptest lateral flow device (RD Biomed Ltd., Hull, UK). After it was confirmed that the test was working correctly, meaning a blue line appeared below the "C" letter on the device, the Peptes kit results were read in the first 15 minutes. A second blue line below the "T" letter on the device meant a positive result. This study was approved by the ethical committee of the Iuliu Hațieganu University of Medicine and Pharmacy Cluj-Napoca. 


\section{Statistics}

Data were entered into a computer using the program R version 3.2.1 (2015-06-18) and analyzed by chi-square and Fischer's test. The prevalence of positive salivary test in both groups was calculated. A P-value $<0.05$ was considered significant.

\section{Results}

\section{Demographic data}

In this study 30 vocal opera students were recruited. As controls were enrolled 20 medical students and residents. As shown in Table I the mean age in the vocal opera group was 23 and in the control group 27 .
In the vocal opera students group $12(40 \%)$ were male and $18(60 \%)$ were female. In the control group $7(35 \%)$ were male and $13(65 \%)$ were female. According to Table II, from 30 vocal opera students only $15(50 \%)$ reported reflux symptoms, $(\mathrm{P}<0.001)$ of which the main symptoms were heartburn and hoarseness (see Figure 1). Peptest was positive in $96.67 \%$ cases ( 29 from 30 ) in vocal opera students group versus $30 \%$ (6 from 20), in the control group $\mathrm{P}<0.001$.

According to the data of the study a vocal opera student presents the probability of 3.22 ( $95 \%$ confidence interval, CI 1.64 - 6.31) of having a positive Peptest compared to the general population.

Table I. Demographic characteristics and lifestyle in study groups.

\begin{tabular}{|l|c|c|c|} 
Group & $\begin{array}{c}\text { Control } \\
(\mathbf{n = 2 0 )}\end{array}$ & $\begin{array}{c}\text { Vocal opera students } \\
(\mathbf{n = 3 0 )}\end{array}$ & p-value \\
\hline Gender (m), n (\%) & $7(35)$ & $12(40)$ & 0.721 \\
Age (years), median (IQR) & $27(23.75-28.25)$ & $23(20-24)$ & $\mathbf{0 . 0 0 2}$ \\
Place of residence (urban), n(\%) & $14(70)$ & $25(83.33)$ & 0.311 \\
Smoking, n(\%) & $2(10)$ & $3(10)$ & 1 \\
& every day: $1(5)$ & every day: $1(3.33)$ & \\
Alcohol, n $(\%)$ & no: $8(40)$ & noccasional: $15(50)$ &
\end{tabular}

Table II. Reflux symptoms and Peptest results in study groups.

\begin{tabular}{|l|c|c|c|} 
Group & $\begin{array}{c}\text { Controls } \\
(\mathbf{n = 2 0})\end{array}$ & $\begin{array}{c}\text { Vocal opera students } \\
(\mathbf{n = 3 0 )}\end{array}$ & p-value \\
\hline Reflux symptoms, $\mathrm{n}(\%)$ & $0(0)$ & $15(50)$ & $<\mathbf{0 . 0 0 1}$ \\
Peptest (positive ), n (\%) & $6(30)$ & $29(96.67)$ & $<\mathbf{0 . 0 0 1}$
\end{tabular}

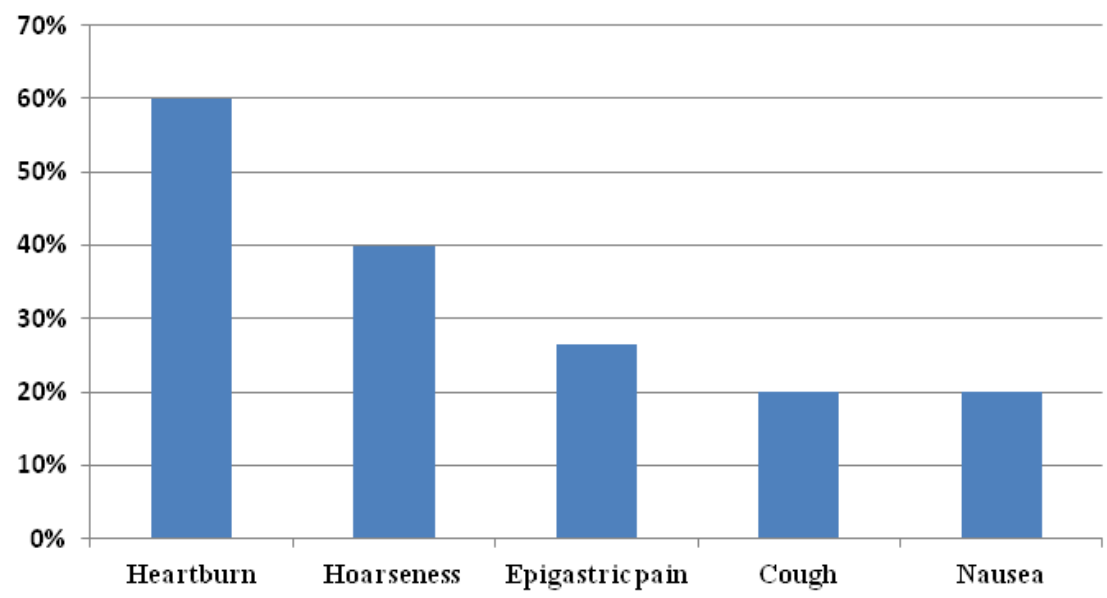

Figure 1. Reflux symptoms in vocal opera students group. 


\section{Discussion}

The aim of the study was to evaluate gastroesophageal reflux in vocal opera students using salivary Peptest. This is the first medical study in which GERD is assessed in this professional category by using a biological diagnostic test. The results of the study showed that although only half of those included in the study group reported reflux symptoms, almost all of them had a positive salivary test. Vocal opera students presented not only GERD symptoms, but also items of dyspepsia; $26 \%$ of the symptomatic one accused epigastric pain and $20 \%$ nausea.

It should be noted that there is a wide age range in both groups, because each studied group had 1 subject who exceeded by far the average age.

An important aspect would be the fact that episodes of reflux are maintained by vocal performance, so the persistence of the symptomatology in these patients is a risk factor for the onset of chronic reflux laryngitis or its aggravation, a fact that may compromise the continuation of artistic careers of professional singers by negatively interfering with their professional performances. Camarota et al. reported clinical cases in which opera singers complained of worsening of the disease symptomatology during performing singing tasks with the ineffectiveness of administering antacid therapy [26]. Yet, the results of our study were based on singers who are only at the beginning of their career.

The laryngeal examination made on 96 professional voice users (in which were included also opera singers) revealed a high prevalence of changes in the true vocal cords, false vocal cords and laryngeal mucosa in general [27]. The mucosal exposure to acid and pepsin leads to numerous macroscopic and microscopic histopathological changes in the mucosa of the vibratory margin of the vocal folds, modifications which are responsible for the hoarseness, thus producing the impairment of the subjective and objective voice quality [28].

We might conclude that gastroesophageal reflux affects a large percentage of the vocal opera students, this condition being occupation related, even if they have not performed for a long time. This fact raises the question if opera singers should be followed in time for severe chronic reflux complications, especially for esophagitis, Barrett's esophagus, adenocarcinoma and also, very important, laryngeal cancer. A study performed in 2015 on 30 patients with T1 laryngeal carcinoma has demonstrated that in these subjects there are significantly higher levels of laryngeal reflux disease components in the saliva (high level of bile acids, the total pepsin and the pepsin enzymatic activity) [29], so there is a clear link between laryngeal reflux and the malignant pathology. What would be the right conduct in terms of preventing these complications and altering voice quality in these patients?

Another aspect should be mentioned, namely that adolescents are more likely to have a higher prevalence of gastroesophageal reflux, which could increase the number of positive tests in this case. There are 3 studies in the medical literature that demonstrates this [30-32].

Although it is a known fact that opera singers have a low compliance in terms of performing invasive diagnostic maneuvers for GERD for fear of having their vocal cords harmed, we have not found any data in the medical research regarding the refusal of esophageal intubation or catheterization in these patients and we also did not evaluate this aspect in our study.

The present study has its limitations given that it was performed on a small number of patients and it was also not possible to perform $\mathrm{pH}$-metry or superior digestive endoscopy to compare the results obtained from salivary tests. Further studies are needed.

\section{Conclusions}

Vocal opera students are at high risk of developing gastroesophageal reflux. Non-invasive salivary Peptest could be a useful tool in diagnosing GERD in these patients. However, this fact has to be confirmed by further studies.

\section{References}

1. Vakil N, Van Zanten SV, Kahrilas P, Dent J, Jones R; Global Consensus Group. The Montreal definition and classification of gastroesophageal reflux disease: a global evidence-based consensus. Am J Gastroenterol. 2006;101:1900-1920; quiz 1943.

2. Kim YS, Kim N, Kim GH. Sex and Gender Differences in Gastroesophageal Reflux Disease. J Neurogastroenterol Motil. 2016;22:575-588.

3. Johnston N, Knight J, Dettmar PW, Lively MO, Koufman J. Pepsin and carbonic anhydrase isoenzyme III as diagnostic markers for laryngopharyngeal reflux disease. Laryngoscope. 2004;114:2129-2134.

4. Johnston N, Wells CW, Blumin JH, Toohill RJ, Merati AL. Receptor-mediated uptake of pepsin by laryngeal epithelial cells. Ann Otol Rhinol Laryngol. 2007;116:934-938.

5. Johnston N, Wells CW, Samuels TL, Blumin JH. Pepsin in nonacidic refluxate can damage hypopharyngeal epithelial cells. Ann Otol Rhinol Laryngol. 2009;118:677-685.

6. Johnston N, Dettmar PW, Lively MO, Postma GN, Belafsky $\mathrm{PC}$, Birchall M, et al. Effect of pepsin on laryngeal stress protein (Sep70, Sep53, and Hsp70) response: role in laryngopharyngeal reflux disease. Ann Otol Rhinol Laryngol. 2006;115:47-58.

7. RDbiomed. PeptestTM Overview. Available from: http:// www.rdbiomed.com/peptest/overview/.

8. Hayat JO, Gabieta-Somnez S, Yazaki E, Kang JY, Woodcock A, Dettmar P, et al. Pepsin in saliva for the diagnosis of gastro-oesophageal reflux disease. Gut. 2015;64:373-380.

9. Saritas Yuksel E, Hong SK, Strugala V, Slaughter JC, Goutte M, Garrett CG, et al. Rapid salivary pepsin test: blinded assessment of test performance in gastroesophageal reflux disease. Laryngoscope. 2012;122:1312-1316. 
10. de Bortoli N, Savarino E, Furnari M, Martinucci I, Zentilin $\mathrm{P}$, Bertani L, et al. Use of a non-invasive pepsin diagnostic test to detect GERD: correlation with MII-pH evaluation in a series of suspected NERD patients. A pilot study. Dig Liv Dis. 2013;45:S68-S69.

11. Ocak E, Kubat G, Yorulmaz I. Immunoserologic pepsin detection in the saliva as a non-invasive rapid diagnostic test for laryngopharyngeal reflux. Balkan Med J. 2015;32:46-50.

12. Hayat JO, Yazaki E, Moore AT, Hicklin L, Dettmar P, Kang JY, et al. Objective detection of esophagopharyngeal reflux in patients with hoarseness and endoscopic signs of laryngeal inflammation. J Clin Gastroenterol. 2014:48:318-327.

13. Du X, Wang F, Hu Z, Wu J, Wang Z, Yan C, et al. The diagnostic value of pepsin detection in saliva for gastroesophageal reflux disease: a preliminary study from China. BMC Gastroenterol. 2017;17:107.

14. Formánek M, Komínek P, Matoušek P, Tomanova R, Urban O, Zeleník K. Comparison of Three Methods Used in the Diagnosis of Extraesophageal Reflux in Children with Chronic Otitis Media with Effusion. Gastroenterol Res Pract. 2015;2015:547959.

15. Formánek M, Zeleník K, Komínek P, Matoušek P. Diagnosis of extraesophageal reflux in children with chronic otitis media with effusion using Peptest. Int J Pediatr Otorhinolaryngol. 2015;79:677-679.

16. Wang YF, Yang CQ, Chen YX, Cao AP, Yu XF, Yu Y, et al. Validation in China of a non-invasive salivary pepsin biomarker containing two unique human pepsin monoclonal antibodies to diagnose gastroesophageal reflux disease. J Dig Dis. 2019;20:278-287.

17. Marshall S, McCann AJ, Samuels TL, Blair A, Bonne V, Johnston N, et al. Detection of pepsin and IL-8 in saliva of adult asthmatic patients. J Asthma Allergy. 2019;12:155-161.

18. Barona-Lleo L, Barona-De Guzman R, Krstulovic C. The Diagnostic Usefullness of the Salivary Pepsin Test in Symptomatic Laryngopharyngeal Reflux. J Voice. 2018. doi: 10.1016/j.jvoice.2018.07.008

19. Spyridoulias A, Lillie S, Vyas A, Fowler SJ. Detecting laryngopharyngeal reflux in patients with upper airways symptoms: Symptoms, signs or salivary pepsin? Respir Med. 2015;109:963-969.

20. Klimara MJ, Johnston N, Samuels TL, Visotcky AM, Poetker DM, Loehrl TA, et al. Correlation of salivary and nasal lavage pepsin with MII-pH testing. Laryngoscope. 2019. doi: 10.1002/lary.28182.
21. Iannella G, Vicini C, Polimeni A, Greco A, Gobbi R, Montevecchi F, et al. Laryngopharyngeal Reflux Diagnosis in Obstructive Sleep Apnea Patients Using the Pepsin Salivary Test. Int J Environ Res Public Health. 2019;16(11):2056. doi: 10.3390/ijerph16112056.

22. Cammarota G, Masala G, Cianci R, Palli D, Capaccio P, Schindler A, et al. Reflux symptoms in professional opera choristers. Gastroenterology. 2007;132:890-898.

23. Pregun I, Bakucz T, Banai J, Molnár L, Pavlik G, Altorjay I, et al. Gastroesophageal reflux disease: work-related disease? Dig Dis. 2009;27:38-44.

24. Hočevar-Boltežar I, Šereg-Bahar M, Kravos A, Mumović G, Mitrović S. Is an occupation with vocal load a risk factor for laryngopharyngeal reflux: a prospective, multicentre, multivariate comparative study. Clin Otolaryngol. 2012;37:362-368.

25. Lenti MV, Cammarota G, Vidali F, Masala G, Bendinelli B, Gasbarrini G, et al. Reflux symptoms in professional opera soloists. Dig Liver Dis. 2019;51:798-803.

26. Cammarota G, Elia F, Cianci R, Galli J, Paolillo N, Montalto $\mathrm{M}$, et al. Worsening of gastroesophageal reflux symptoms in professional singers during performances. J Clin Gastroenterol. 2003;36:403-404.

27. Cobzeanu MD, Voineag M, Drug VL, Ciubotaru A, Cobzeanu BM, Palade OD. Laryngeal morphological changes due to gastroesophageal reflux disease. Rev Med Chir Soc Med Nat Iasi. 2012;116:1011-1015.

28. Lechien JR, Saussez S, Harmegnies B, Finck C, Burns JA. Laryngopharyngeal Reflux and Voice Disorders: A Multifactorial Model of Etiology and Pathophysiology. J Voice. 2017;31:733-752.

29. Sereg-Bahar M, Jerin A, Hocevar-Boltezar I. Higher levels of total pepsin and bile acids in the saliva as a possible risk factor for early laryngeal cancer. Radiol Oncol. 2015;49:5964.

30. Riaz H, Kamal SW, Aziz S. Gastroesophageal reflux disease (GERD) in students of a government medical college at Karachi. J Pak Med Assoc. 2010;60:147-150.

31. Chen JH, Wang HY, Lin HH, Wang CC, Wang LY. Prevalence and determinants of gastroesophageal reflux symptoms in adolescents. J Gastroenterol Hepatol. 2014;29:269-275.

32. Reshetnikov OV, Kurilovich SA, Denisova DV. Symptoms of gastroesophageal reflux disease and associated factors in adolescents: population survey. Eksp Klin Gastroenterol. 2013;12:8-14 